\title{
The immunohistochemical profile of Spitz nevi and conventional (non-Spitzoid) melanomas: a baseline study
}

\author{
María C Garrido-Ruiz ${ }^{1,6}$, Luis Requena ${ }^{2}$, Pablo Ortiz³ ${ }^{3}$ Beatriz Pérez-Gómez ${ }^{4}$, \\ Soledad R Alonso ${ }^{5}$ and José Luis Rodríguez Peralto ${ }^{1}$
}

${ }^{1}$ Department of Pathology, 12 de Octubre University Hospital, Madrid, Spain; ${ }^{2}$ Department of Dermatology, Fundación Jiménez Díaz, Madrid, Spain; ${ }^{3}$ Department of Dermatology, 12 de Octubre University Hospital, Madrid, Spain; ${ }^{4}$ Environmental and Cancer Epidemiology Unit, National Center for Epidemiology (CIBERESP), Carlos III Institute of Health, Madrid, Spain and ${ }^{5}$ Department of Pathology, Guadalajara Hospital, Guadalajara, Spain

\begin{abstract}
Several isolated markers have been proposed to aid in differential diagnostic of difficult melanocytic lesions, albeit none has been shown to be definitive in differentiating Spitz nevus from melanoma. This study proposes a wide panel of 22 markers having important functions in different biological functions (cell cycle, apoptosis, DNA repair proteins and membranous receptors) to provide a combination of proteins associated with either benign or malignant phenotype. Using tissue microarrays, we compared protein expression profiles in 28 typical Spitz nevi and 62 primary vertical growth phase non-spitzoid melanomas. Most of the significant differences were linked to cell-cycle deregulation such as overexpression of cyclin D1 and p21 in Spitz nevi compared with non-spitzoid melanomas (74 vs $16 \%$ and 91 vs $27 \%$, respectively) and mitotic rate including Ki67 , highly expressed in deep areas of non-spitzoid melanomas (37\%), whereas it is not expressed in Spitz nevi $(0 \%)$, topoisomerase $11 \alpha(79 \%$ in non-spitzoid melanomas vs $15 \%$ in Spitz nevi) and nuclear survivin $(69 \%$ in melanomas vs $0 \%$ in Spitz nevi). A combination of biological markers differentially expressed in Spitz nevi from non-spitzoid melanomas is defined, thus providing a potential tool for histopathological differential diagnostic between Spitz nevus and melanoma. Nevertheless, more studies including atypical Spitz nevi and spitzoid melanomas are necessary to further establish a reliable panel to differentiate among difficult cases. Modern Pathology (2010) 23, 1215-1224; doi:10.1038/modpathol.2010.102; published online 11 June 2010
\end{abstract}

Keywords: immunohistochemistry; melanoma; Spitz nevus; tissue microarrays

Spitz nevus is an acquired melanocytic lesion, which generally develops in children and adolescents, although it is not rare in adults. It is classically believed to be benign, and conservatively managed. However, since its description in 1948 by Sophie Spitz, ${ }^{1}$ its diagnosis has been a cause for concern because it is not always possible to render an unequivocal diagnosis of Spitz nevus vs melanoma.

Correspondence: Dr JL Rodríguez Peralto, Department of Pathology, Hospital Universitario 12 de Octubre, Avda de Córdoba s/n, Madrid 28041, Spain.

E-mail: jrodriguezp.hdoc@salud.madrid.org

${ }^{6}$ Current address: UCSF Helen Diller Family Comprehensive Cancer Center, University of California at San Francisco, San Francisco, CA, USA.

Received 14 October 2009; revised and accepted 15 February 2010; published online 11 June 2010
Although certain features are now systematically evaluated to distinguish between Spitz nevi and melanomas, diverse experts may vary in defining the relative importance of each of the following criterion: size, shape, circumscription of junctional nests, upward spread in the epidermis, extention into the subcutis, eosinophilic globules, mitotic figures and their superficial or deep location within the tumor, giant cells, presence of ulceration and stromal alterations. ${ }^{2-5}$ Furthermore, most lesions do not show many of the conventional criteria that are used routinely for the histopathologic diagnosis of the tumor, thus emphasizing the lack of objective criteria for predicting the biologic behavior of such lesions., ${ }^{3,6,7}$ The classification of some cases as metastasizing Spitz nevi ${ }^{1}$ illustrates the difficulty of accurately distinguishing some Spitz nevi from melanoma based solely 
on histological criteria. Thus, the diagnostic term 'atypical Spitz tumor' is used to describe lesions that deviate from the typical appearance of Spitz nevi and have an uncertain biological significance. ${ }^{7}$

Given that the diagnosis of a subset of lesions remains challenging, the purpose of this study was to evaluate the expression of a wide panel of markers using routine immunohistochemical methods to provide a universally available set of proteins to distinguish between Spitz nevus and melanoma. We compared the protein expression signatures in both series of typical Spitz nevi and vertical growth phase melanomas in an attempt to establish a powerful tool allowing the prediction of biological behavior of the melanocytic lesions. The results provide a set of nine markers differentially expressed in Spitz nevi vs melanomas useful in differential diagnostic of both melanocytic lesions.

\section{Materials and methods}

\section{Tissue Samples and Tissue Arrays Construction}

We studied a total of 90 formalin-fixed paraffinembedded samples from the files of the Pathology Department, 12 de Octubre University Hospital, Madrid, collected from 1995 to 2005. Twenty eight corresponded to typical Spitz nevi, concordant with the features of nests of spindle and/or epithelioid melanocytes, size $<7 \mathrm{~mm}$, maturation, symmetry, no pagetoid spread and no mitosis or pushing margins at the base, ${ }^{3}$ and 62 primary vertical growth phase non-spitzoid melanomas. Vertical growth phase was defined after pre-established criteria: ${ }^{8}$ all tumor cell nests in the epidermis being smaller than at least one of the dermis, the presence of dermal tumor cell nests of 25 or more cells in width and mitotic activity in intradermal neoplastic cells. Melanoma patients were treated after standard criteria: surgical resection with adequate margins. Adjuvant therapies with interferon or chemotherapy for metastatic disease were used when clinically indicated.

Representative sections stained with hematoxylin-eosin were evaluated for histological features by the authors, and blocks were selected on the basis of suitable tissue (at least 1-mm thick) ${ }^{9}$ to construct the tissue arrays.

A tissue microarray containing Spitz nevi and two more with VGP melanomas were assembled as described earlier, ${ }^{9}$ including at least two $1.5 \mathrm{~mm}$ diameter cylinders of highly cellular areas from the primary paraffin blocks. In addition, normal tissues (mostly reactive lymphatic nodes, tonsil and skin) were placed in the arrays as internal controls.

\section{Immunohistochemistry and Scoring System}

Immunohistochemical staining was performed on $3 \mu \mathrm{m}$ tissue sections from the tissue microarray blocks using 22 different primary antibodies against biologically relevant proteins (source and concentration listed in Table 1). Immunodetection was performed with either the LSAB visualization system or Envision (both from Dakocytomation, Glostrup, Denmark) using diaminobenzidine chromogen as substrate. All sections were counter-stained with hematoxylin (DAKO).

Negative controls were obtained by omitting the primary antibody. The selection of the threshold and

Table 1 Antibodies used in the study indicating clone, source, dilution, visualization method, scoring, threshold and positive controls

\begin{tabular}{|c|c|c|c|c|c|c|}
\hline Protein & Clone & Source & Dilution & $\begin{array}{l}\text { Visualization } \\
\text { system }\end{array}$ & Threshold & Positive control \\
\hline N-cadherin & 3B9 & Zymed & $1: 10$ & LSAB/DAB & $\geq 5 \%$ membranous & Cardiac muscle \\
\hline E-cadherin & 4A2C7 & Zymed & $1: 100$ & $\mathrm{LSAB} / \mathrm{DAB}$ & $\geq 5 \%$ membranous & Epithelial cells \\
\hline Caveolin & 2297 & Transduction & $1: 25$ & $\mathrm{LSAB} / \mathrm{DAB}$ & $\geq 50 \%$ membranous & Endothelial cells \\
\hline CDK 4 & 35 & Chemicon & $1: 100$ & $\mathrm{LSAB} / \mathrm{DAB}$ & $\geq 5 \%$ nuclear & Proliferating cells \\
\hline Cyclin D1 & DCS-6 & DAKO & $1: 100$ & $\mathrm{LSAB} / \mathrm{DAB}$ & $\geq 30 \%$ nuclear & Endothelial cells, macrophages \\
\hline C-Kit & Polyclonal & DAKO & $1: 50$ & $\mathrm{LSAB} / \mathrm{DAB}$ & $\geq 50 \%$ membranous & Normal skin melanocytes \\
\hline Ki-67 & MIB 1 & DAKO & $1: 100$ & $\mathrm{LSAB} / \mathrm{DAB}$ & $\geq 20 \%$ nuclear & Proliferating cells \\
\hline $\mathrm{HLA}^{*}$ & J576 & CNIO & $1: 150$ & LSAB/DAB & Any nuclear expression & GC cells \\
\hline HMB-45 & HMB-45 & BIOGENEX & $1: 10$ & LSAB/DAB & $\geq 50 \%$ cytoplasmic & Normal skin melanocytes \\
\hline MELAN A & A103 & DAKO & $1: 10$ & LSAB/DAB & $\geq 50 \%$ cytoplasmic & Normal skin melanocytes \\
\hline MLH-1 & G168-15 & Pharmingen & $1: 100$ & $\mathrm{LSAB} / \mathrm{DAB}$ & $\geq 50 \%$ nuclear & Normal skin \\
\hline MSH-2 & FE11 & ONCOGEN & $1: 100$ & $\mathrm{LSAB} / \mathrm{DAB}$ & $\geq 70 \%$ nuclear & Normal skin \\
\hline Osteopontin & Polyclonal & Abcam & $1: 1.500$ & Envision & $>10 \%$ cytoplasmic & Stromal cells normal skin \\
\hline P16 & F12 & Sta. Cruz & $1: 50$ & $\mathrm{LSAB} / \mathrm{DAB}$ & $\geq 50 \%$ positive cells & Epithelial cells normal skin \\
\hline P21 & EA10 & ONCOGEN & $1: 50$ & $\mathrm{LSAB} / \mathrm{DAB}$ & $\geq 10 \%$ positive cells & Scattered GC cells \\
\hline P53 & DO-7 & Novocastra & $1: 50$ & $\mathrm{LSAB} / \mathrm{DAB}$ & $\geq 10 \%$ positive cells & Scattered GC cells \\
\hline $\mathrm{PKC} \alpha$ & $\mathrm{H} 7$ & Sta. Cruz & $1: 25$ & $\mathrm{LSAB} / \mathrm{DAB}$ & $\geq 50 \%$ cytoplasmic & Small lymphocytes \\
\hline $\mathrm{Rb}$ & Polyclonal & $\mathrm{BD}$ & $1: 250$ & $\mathrm{LSAB} / \mathrm{DAB}$ & $\geq 10 \%$ nuclear & Proliferating cells \\
\hline S-100 & Polyclonal & DAKO & $1: 500$ & $\mathrm{LSAB} / \mathrm{DAB}$ & $\geq 30 \%$ positive cells & Normal melanocytes, nerves \\
\hline SPARC & $15 \mathrm{G} 12$ & Novocastra & $1: 25$ & $\mathrm{LSAB} / \mathrm{DAB}$ & $>10 \%$ cytoplasmic & Endothelial cells in malignant tumors \\
\hline Survivin & Polyclonal & RD Systems & $1: 1.500$ & $\mathrm{LSAB} / \mathrm{DAB}$ & $\geq 2 \%$ nuclear & Scattered GC cells \\
\hline Topoisomerase II $\alpha$ & Ki-S1 & DAKO & $1: 400$ & $\mathrm{LSAB} / \mathrm{DAB}$ & $\geq 10 \%$ nuclear & Proliferative cells \\
\hline WT1 & $6 \mathrm{~F}-\mathrm{H} 2$ & DAKO & $1: 40$ & $\mathrm{LSAB} / \mathrm{DAB}$ & $\geq 10 \%$ positive cells & Mesothelioma \\
\hline
\end{tabular}

*HLA DP, DQ, DR, antibodies provided by the Monoclonal Antibodies Unit (CNiO). 
internal controls for the antibodies were earlier established to facilitate reproducibility of the method according to the published literature ${ }^{9}$ (see Table 1). All cases were independently scored by two pathologists and were recorded as positive taking into account the protein expression in neoplastic cells and the specific cutoff for each marker. Any discrepancies in the percentage of positive cells were resolved by simultaneous re-evaluation of the sections.

\section{Statistical Analysis}

Fisher's exact test was used to assess whether a specific protein expression was associated with a given lesion, either Spitz nevus or melanoma. Statistical significance was concluded for values of $P<0.05$. In addition, adjusted $P$-values were calculated using Hochberg and Benjamini ${ }^{10}$ method to avoid the influence of multiple testing. Clinical and histopathological data were compiled after all statistical studies were performed (Table 2).

\section{Results}

\section{Clinical and Histopathological Features}

The series comprises 90 patients $(52 \%$ females and $48 \%$ males) ranging from 3 to 91 years. The average

Table 2 Clinical and histopathological features of Spitz nevi and melanomas

\begin{tabular}{|c|c|c|}
\hline Variables & $\begin{array}{l}\text { Spitz nevi } \\
\text { c/to (\%) }\end{array}$ & $\begin{array}{c}\text { Melanomas } \\
\text { c/to }(\%)\end{array}$ \\
\hline \multicolumn{3}{|l|}{ Sex } \\
\hline Female & $16 / 28(57 \%)$ & $31 / 62(50 \%)$ \\
\hline Male & $12 / 28(43 \%)$ & $31 / 62(50 \%)$ \\
\hline \multicolumn{3}{|l|}{ Age } \\
\hline Range & $3-51$ & $21-91$ \\
\hline Median & 22 & 64 \\
\hline Mean & 21.6 & 62 \\
\hline \multicolumn{3}{|l|}{ Localization } \\
\hline Head and neck & $2 / 28(7 \%)$ & $10 / 62(16 \%)$ \\
\hline Trunk & $1 / 28(4 \%)$ & $19 / 62(31 \%)$ \\
\hline Extremities & $13 / 28(46 \%)$ & $8 / 62(13 \%)$ \\
\hline Acral & $0 / 28(0 \%)$ & $8 / 62(13 \%)$ \\
\hline NA & $12 / 28(43 \%)$ & $17 / 62(27 \%)$ \\
\hline Ulceration & - & $21 / 62(34 \%)$ \\
\hline Breslow's index & - & \\
\hline$<1 \mathrm{~mm}$ & & $8 / 62(13 \%)$ \\
\hline $1-2 \mathrm{~mm}$ & & $11 / 62(19 \%)$ \\
\hline$>1 \mathrm{~mm}$ & & $43 / 62(69 \%)$ \\
\hline \multicolumn{3}{|l|}{ Histological subtype } \\
\hline Superficial spreading melanoma & - & $29 / 62(47 \%)$ \\
\hline Nodular melanoma & - & $20 / 62(32 \%)$ \\
\hline Lentigo maligna melanoma & - & $5 / 62(8 \%)$ \\
\hline Acral lentiginous melanoma & - & $8 / 62(13 \%)$ \\
\hline Metastases & - & $35 / 62(56 \%)$ \\
\hline Outcome & - & $20 / 62(32 \%)$ \\
\hline
\end{tabular}

ages for Spitz nevi and melanoma patients were 21.6 and 62 years, respectively. Location of the lesions was known in 71 out of 90 cases $(79 \%)$, the most common being the extremities for Spitz nevi $(46 \%)$ and the trunk for melanomas (31\%). All Spitz nevi patients were alive with no metastasis, whereas $56 \%$ (35 out of 62 ) vertical growth phase melanomas developed metastasis and $34 \%$ (21 out of 62) died.

Most cases of Spitz nevi showed epithelioid or spindle melanocytes with no significant cytological atypia (Figure 1). Neither mitotic figures nor pagetoid extension were seen in any of the 28 cases of Spitz nevi. The histological examination of melanomas (Figure 2) revealed that the most common melanoma subtype, according to the World Health Organization Classification for melanoma, was superficial spreading melanoma (29 of 62 cases, $47 \%)$. Twenty one out of 62 cases of melanoma (34\%) were ulcerated and $69 \%$ (43 of 62 cases) had Breslow's index $>1 \mathrm{~mm}$. Most of them presented with metastasis when diagnosed (35 of 62 cases, $56 \%$ ). Table 2 summarizes clinical and histopathological data of this series.

\section{Expression Profiling in Spitz Nevi and Melanoma}

The results of protein expression in Spitz nevi and melanoma are detailed in Tables 3 and 4 and illustrated in Figure 3. Immunostaining for melanocytic specific markers showed S-100 positivity in all cases, melan-A expression in the majority of Spitz nevi (96\%) and melanomas (92\%), whereas HMB-45 was only expressed in $44 \%, 12$ out of 27 cases of Spitz nevi compared with $95 \%$ (59 of 62) in melanoma cases.

Regarding cell-cycle regulators, cyclin D1 showed high levels of expression in Spitz nevi (17 of 23, $74 \%$ ) and was significantly decreased in primary vertical growth phase melanomas (10 of $61,16 \%$ ). No significant changes were found in p16, p53 or $\mathrm{Rb}$, whereas strikingly higher nuclear positivity was noted for p21 in the majority of Spitz neoplasm (91\%, 21 of 23) compared with malignant tumors, in which p21 was only expressed in $27 \%$ (17 of 62 ) of cases (Figure 3).

The proliferative activity was assessed using Ki-67 and topoisomerase II $\alpha$ immunostainings. Spitz nevi exhibited significant lower rate of $\mathrm{Ki}-67$ and topoisomerase II $\alpha$, as there were very few cells staining positively $(<20 \%)$ for Ki-67 and only few cases $(15 \%, 4$ of 26$)$ stained positively for topoisomerase II $\alpha$ in Spitz nevi; however, 37\% (23 of 62) and $79 \%$ (49 of 62 ) of melanomas showed nuclear positivity for Ki-67 hazardly distributed and topoisomerase II $\alpha$, respectively. In addition to the observed differences in proliferative activity between Spitz nevi and melanomas, in Spitz nevi most of the mitotic figures were confined to the junctional or superficial component of the neoplasm, whereas in 

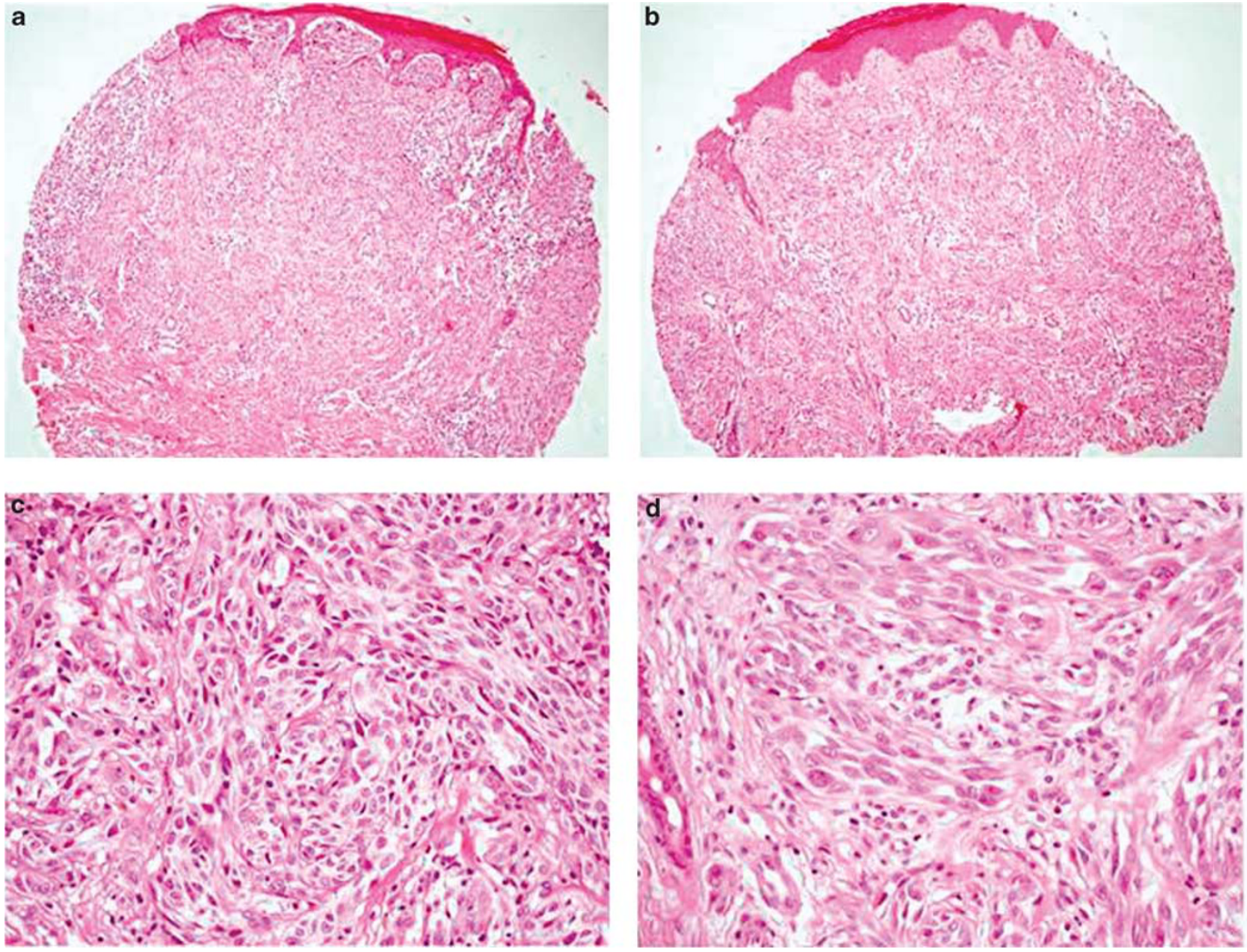

Figure 1 Two cylinders from typical Spitz nevi (H\&E; original magnification: $\times 100(\mathbf{a}, \mathbf{b})$ and $\times 400(\mathbf{c}, \mathbf{d})$ ).

melanomas, they were scattered throughout the entire thickness of the neoplasm. Nuclear expression of the apoptotic inhibitor survivin was negative in all nevi, and frequently expressed (42 of 62, 68\%) in melanomas (Figure 3).

In the group of membrane receptors, caveolin showed significant loss of expression in vertical growth phase melanomas (19 of $62,31 \%$ ) compared with Spitz nevi (16 of 26, 62\%) as shown in Figure 3.

Concerning cell-matrix transition proteins, both osteonectin (SPARC) and protein kinase $\mathrm{C} \alpha(\mathrm{PKC} \alpha)$ earlier well recognized to have an important function in local invasion, ${ }^{11}$ have shown to be significantly overexpressed in Spitz nevi (25 of 26, 96\% for both markers) compared with melanomas (23 of 53, $43 \%$ and 26 of $54,48 \%$, respectively).

\section{Discussion}

In 1910, Darier and Civatte ${ }^{12}$ described an unusual melanocytic tumor developing rapidly on the nose of a young child. One century later, although guidelines have been proposed for diagnosis, the inability to accurately interpret many of such Spitz tumors and to know their biological potential still makes the diagnosis difficult. ${ }^{7}$ The most typical or banal Spitz tumors share particular features with conventional acquired nevi. However, the problem with the indiscriminate use of 'nevus' is that it connotes a completely benign status and a priori presents no risk to the patient. This is not the case for a subset of spitzoid tumors as it has clearly been shown. ${ }^{1,13,14}$ Despite all the efforts, some proportion of lesions seems impossible to distinguish from melanoma, and rare lesions behave aggressively so that an intermediate or third category lesions difficult to classify as clearly benign or malignant has raised. ${ }^{6}$ Several authors have favored the term 'Spitz-like or atypical Spitz tumor' defining a spectrum of lesions extending from benign nevus to malignant spitzoid melanoma. ${ }^{3,6,7,14}$ Such a complex context raises the possibility of inaccurate diagnoses that could actually be classified as either benign or malignant, thus avoiding imprecise terms in the histopathologic reports. ${ }^{15}$

Recently, it seems that comparative genomic hybridization and fluorescence in situ hybridization on lesional tissues represent helpful adjunctive 

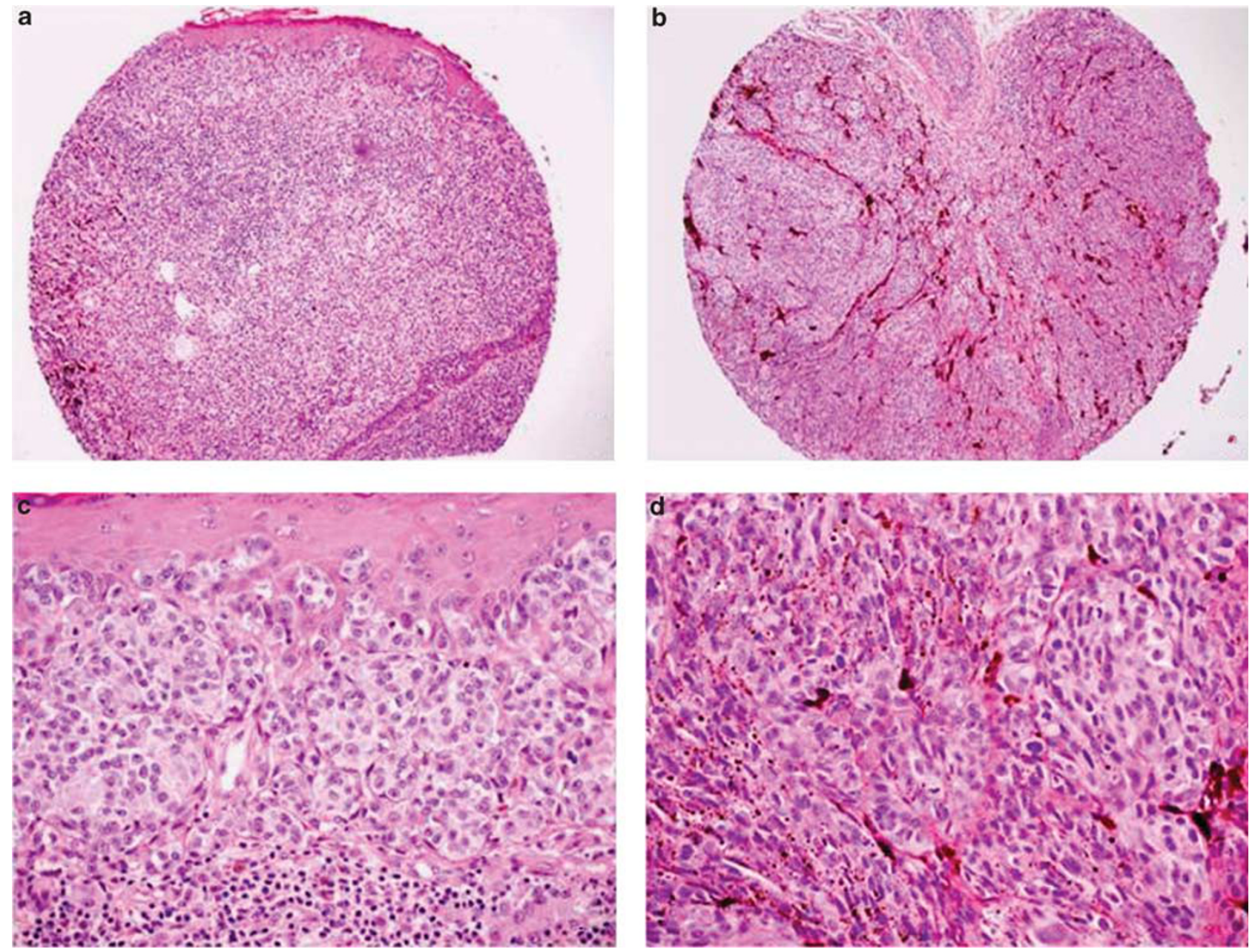

Figure 2 Two cylinders from primary VGP melanomas (H\&E; original magnification: $\times 100(\mathbf{a}, \mathbf{b})$ and $\times 400(\mathbf{c}, \mathbf{d})$ ).

techniques in difficult cases of spitzoid melanocytic neoplasms, ${ }^{16-21}$ although these high-resolution molecular techniques are still not widely available and are sometimes difficult to interpret. Thus, further studies are necessary to evaluate these techniques as diagnostic tools. Histopathologic examination remains the gold standard to distinguish Spitz nevi from melanoma, albeit no objective criteria exist to predict the biologic behavior of a specific lesion. Earlier, several studies, mostly based on the expression of single or few proteins, have tried to shed light on the eternal controversy surrounding spitzoid lesions,,$^{5,15,22,23}$ but no markers are yet known to reliably differentiate between the two neoplasms. Thus, neither HMB-45, AgNOR, cyclin D1, c-myc, c-fos, telomerase, cdc-7, anti-leptin receptor, BCL-2, p53 nor p16 proved helpfulness in distinguishing Spitz nevi from melanoma. ${ }^{13,24-33}$

In this study, we performed a comparative analysis of protein expression using a wide panel of antibodies between classical Spitz nevi and vertical growth phase melanomas. Using tissue microarray analysis, a high-throughput means that allows the evaluation of several markers in a large number of melanocytic tumors, we identified a specific protein expression profile differentiating between typical Spitz nevus and non-spitzoid melanoma (Table 2).

This study primarily shows that Spitz nevi displays evidence of cell-cycle deregulation specially in an increased cyclin D1, p16, p53 and Rb expression, which in part accounts for the overlapping immunoprofile seen in Spitz nevi and melanoma. ${ }^{2,29,31}$ However, one of the most striking data observed in this study is that p21, an inhibitor of the cell-cycle progression at the G1/S transition, is found to be significantly overexpressed in Spitz nevi compared with melanoma expression, in agreement with earlier studies. ${ }^{2,31,34}$ These data support the important function of p21 in Spitz nevus induced senescence that may be crucial for protection against malignant progression. It seems likely that elevated levels of p21 reflect unknown regulatory changes within the p21 pathway independent of p53. The absence of correlation between p53 gene mutation and p21 expression has already been shown in different tumors. ${ }^{35}$ Moreover, no relationship has been found between expression 
Table 3 Contingency analysis (Fisher's exact test) comparing the level of protein expression in Spitz nevi and vertical growth phase (VGP-) melanomas

\begin{tabular}{|c|c|c|c|c|c|c|}
\hline & \multicolumn{2}{|c|}{ Spitz nevi } & \multicolumn{2}{|c|}{ VGP melanomas } & \multicolumn{2}{|c|}{ Spitz/melanoma } \\
\hline & c/to & $\%(+) S$ & c/to & $\%(+) V$ & $p(S / V)$ & $p(S / V)^{*}$ \\
\hline HMB 45 & $12 / 27$ & 44 & $59 / 62$ & $95 \%$ & 0.000 & 0.000 \\
\hline Melan A & $26 / 27$ & 96 & $57 / 62$ & 92 & 0.663 & 1.000 \\
\hline S-100 & $27 / 27$ & 100 & $62 / 62$ & 100 & 1.000 & 1.000 \\
\hline Cyclin D1 & $17 / 23$ & 74 & $14 / 61$ & 16 & 0.000 & 0.000 \\
\hline p16 & $26 / 26$ & 100 & $55 / 62$ & 89 & 0.099 & 0.237 \\
\hline p21 & $21 / 23$ & 91 & $17 / 62$ & 27 & 0.000 & 0.000 \\
\hline p53 & $20 / 26$ & 77 & 49/62 & 79 & 1.000 & 1.000 \\
\hline $\mathrm{Rb}$ & $17 / 26$ & 65 & $46 / 62$ & 74 & 0.443 & 0.824 \\
\hline Survivin & $0 / 26$ & 0 & $42 / 62$ & 68 & 0.000 & 0.000 \\
\hline MLH-1 & $28 / 28$ & 100 & $61 / 62$ & 98 & 1.000 & 1.000 \\
\hline MSH-2 & $26 / 26$ & 100 & $61 / 61$ & 100 & 1.000 & 1.000 \\
\hline Ki 67 & $0 / 27$ & 0 & $23 / 62$ & 37 & 0.000 & 0.000 \\
\hline Caveolin & $16 / 26$ & 62 & 19/62 & 31 & 0.009 & 0.026 \\
\hline c-kit & $3 / 26$ & 12 & $17 / 62$ & 27 & 0.163 & 0.372 \\
\hline E-cadherin & $21 / 25$ & 84 & $38 / 62$ & 61 & 0.046 & 0.120 \\
\hline $\mathrm{N}$-cadherin & $5 / 24$ & 21 & $13 / 47$ & 28 & 0.580 & 0.985 \\
\hline SPARC & $25 / 26$ & 96 & $23 / 53$ & 43 & 0.000 & 0.000 \\
\hline Osteopontin & $18 / 27$ & 67 & $34 / 48$ & 71 & 0.796 & 1.000 \\
\hline $\mathrm{PKC} \alpha$ & $25 / 26$ & 96 & $26 / 54$ & 48 & 0.000 & 0.000 \\
\hline WT1 & $15 / 24$ & 63 & $29 / 62$ & 47 & 0.233 & 0.508 \\
\hline HLA & $2 / 25$ & 8 & $5 / 62$ & 8 & 1.000 & 1.000 \\
\hline Topoisomerase II $\alpha$ & $4 / 26$ & 15 & $49 / 62$ & 79 & 0.000 & 0.000 \\
\hline
\end{tabular}

*Adjusted $P$ values to minimize the false discovery rate.

Table 4 Statistically significant markers helping in differential diagnostic between Spitz nevi and melanomas

\begin{tabular}{|c|c|c|c|c|c|}
\hline & \multicolumn{2}{|c|}{ Spitz nevus } & \multicolumn{2}{|c|}{ VGP melanoma } & \multirow[b]{2}{*}{$p(S / V)$} \\
\hline & c/to & $\%(+) N$ & c/to & $\%(+) N$ & \\
\hline HMB 45 & $12 / 27$ & 44 & $59 / 62$ & 95 & 0.000 \\
\hline Cyclin D1 & $17 / 23$ & 74 & $14 / 61$ & 16 & 0.000 \\
\hline p21 & $21 / 23$ & 91 & $17 / 62$ & 27 & 0.000 \\
\hline Survivin & $0 / 26$ & 0 & $42 / 61$ & 69 & 0.000 \\
\hline Ki 67 & $0 / 27$ & 0 & $23 / 62$ & 37 & 0.000 \\
\hline Caveolin & $16 / 26$ & 62 & $19 / 62$ & 31 & 0.009 \\
\hline SPARC & $25 / 26$ & 96 & $23 / 53$ & 43 & 0.000 \\
\hline $\mathrm{PKC} \alpha$ & $25 / 26$ & 96 & $26 / 54$ & 48 & 0.000 \\
\hline Topoisomerase II & $4 / 26$ & 15 & $49 / 62$ & 79 & 0.000 \\
\hline
\end{tabular}

levels of wild-type p53 and p21 protein in melanoma cell lines. ${ }^{36}$ On the other hand, our results strongly suggest a function of cyclin D1 in the development of melanocytic neoplasms, confirming the earlier observations that it is highly expressed in Spitz nevi ${ }^{29}$ and there is a diminished expression in vertical growth phase melanomas toward the deep reticular consistent with earlier reports, which show that cyclin D1 is confined to the superficial component of the tumor. ${ }^{37}$

Unlike melanoma, the cyclin D1 overexpression observed in Spitz nevi does not seem to correlate to cell proliferation. Thus, as earlier observed, Ki-67, a cell-cycle-associated nuclear antigen, nuclear survivin, a mitotic regulator by preserving microtubule stability, ${ }^{38}$ and topoisomerase II $\alpha$, exclusively expressed in the proliferating compartments of normal tissues and tumors, ${ }^{39}$ are significantly increased in melanoma vs nevus. ${ }^{8,40-43}$ Although melanomas show higher proliferation rates (37 vs 0\% in Spitz nevi) when assessed with Ki-67, few cases of Spitz nevi show scattered positive cells at the top of the lesion, whereas melanoma has nuclear labeling throughout the lesion. ${ }^{41,42}$

The structural membrane-scaffolding protein caveolin, with additional function in the transduction of signals from the plasma membrane, showed a loss of expression in vertical growth phase melanomas when compared with nevi. These results are consistent with earlier reports ${ }^{9}$ and support the reduction of its expression and caveolae formation in oncogenically transformed cells. ${ }^{44}$

In addition, some of the protein markers included in our study have been earlier shown to be involved in mediating cell-matrix interactions and have been implicated in melanoma invasion and progression. ${ }^{11}$ This study also reveals a high expression of the serin/threonine kinase PKC $\alpha$ and the secreted protein acidic and rich in cysteine, osteonectin/ SPARC, in Spitz nevi (96\% for both proteins) and a statistically significant difference compared with melanomas (48 and $43 \%$, respectively; $P<0.05$ ). To our knowledge, this is the first report focusing on these proteins to differentiate Spitz nevi from melanoma, although osteonectin has earlier been shown to predict metastasis in melanoma. ${ }^{11,45}$ These observations primarily suggest that the invasion of the deep dermis is not necessarily related to 

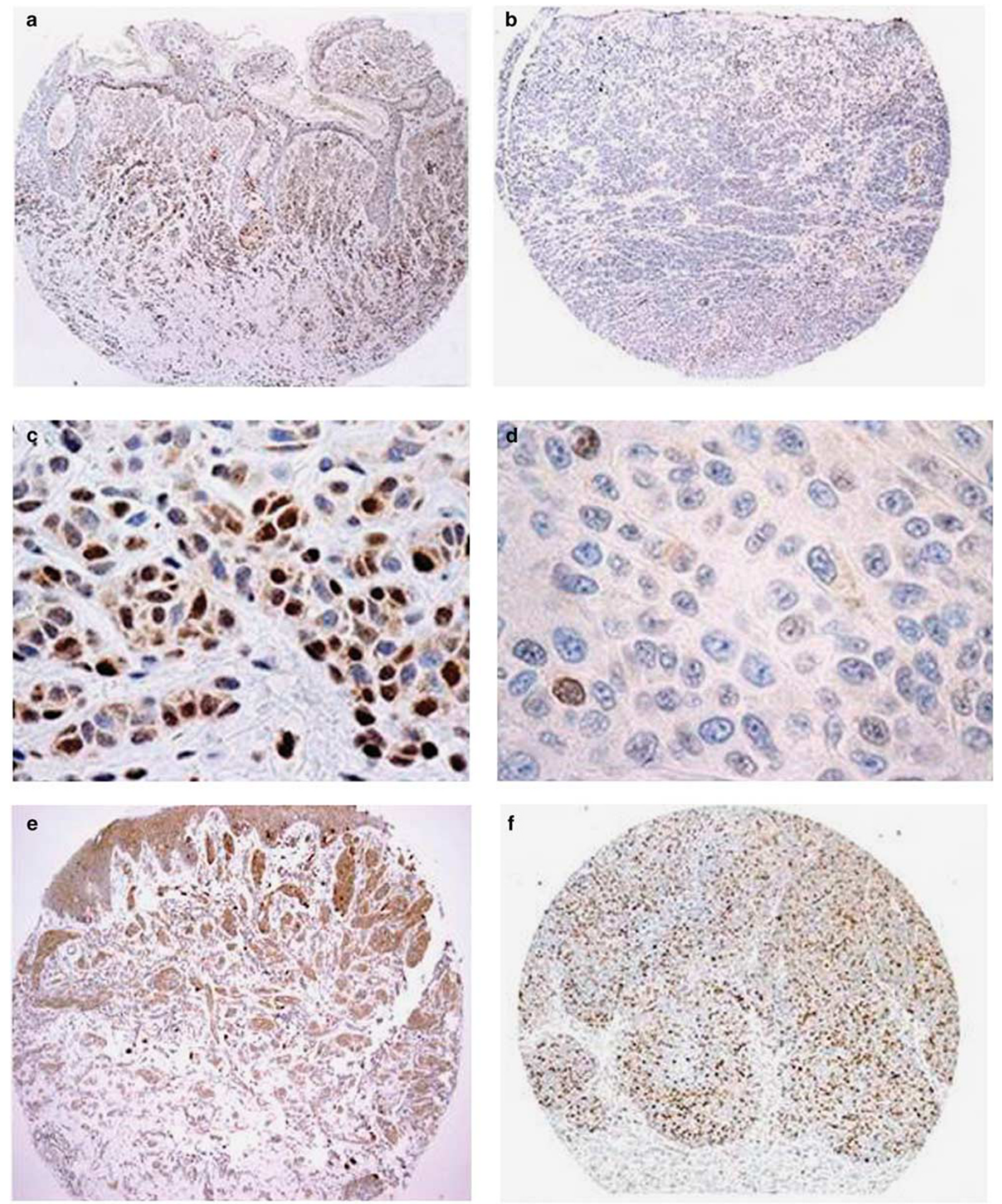

Figure 3 Representative immunohistochemical staining in VGP melanomas and Spitz nevi for significant proteins including p21 (a-d), survivin $(\mathbf{e}-\mathbf{h})$ and caveolin (i-l) (original magnification: $\times 100$ and $\times 400$ ).

malignancy, and identify two new markers that can be used in distinguishing melanomas from Spitz nevi.
None of these findings is separately sufficient to rule out the diagnosis of melanoma, but it seems that the combination of a protein expression panel 

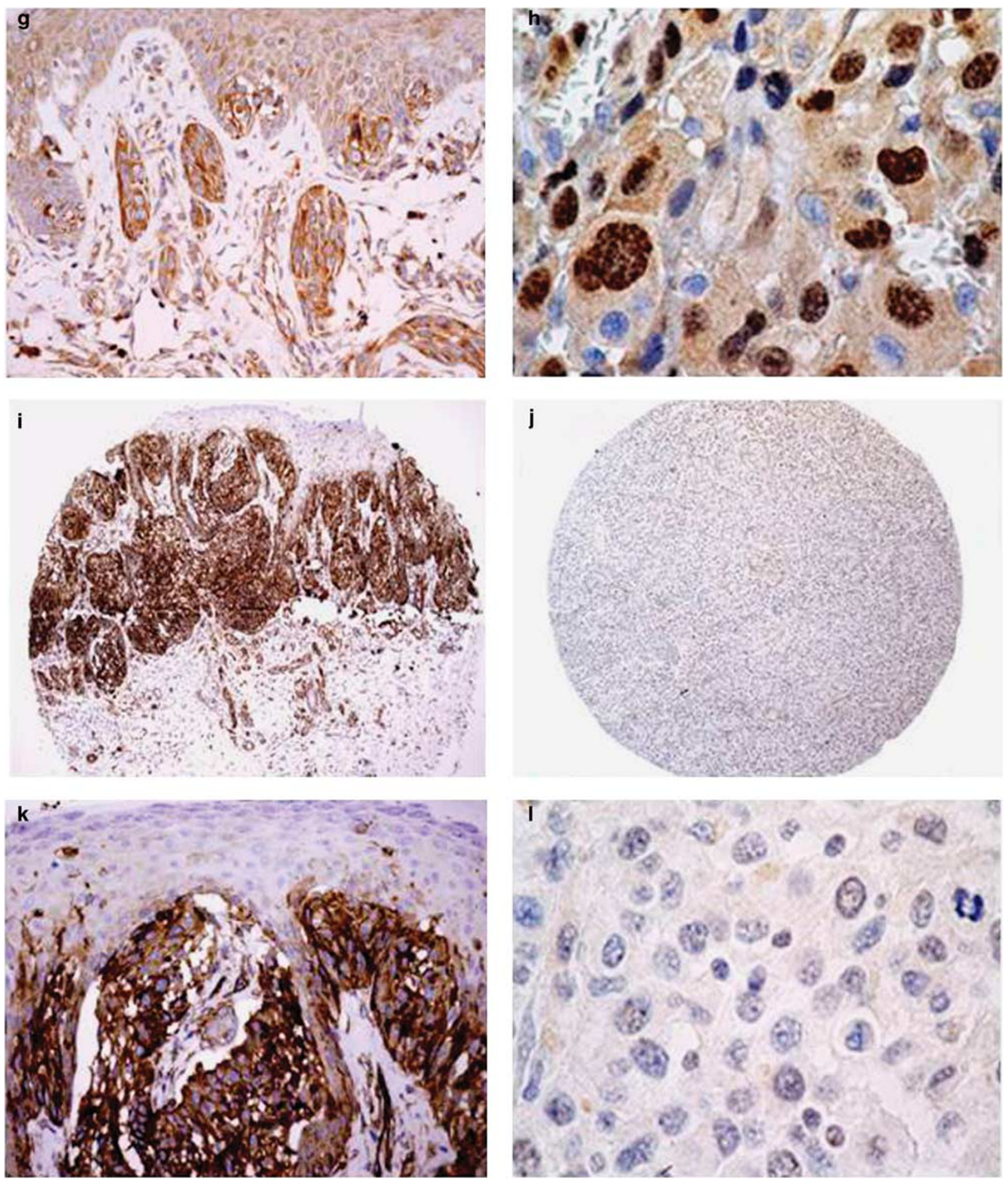

Figure 3 Continued.

including cyclin D1, p21, osteonectin (SPARC), PKC $\alpha$, Ki-67, topoII $\alpha$ and survivin might have a great diagnostic usage in the differentiation of typical Spitz nevus from its malignant mimics. The significantly different expression observed in Spitz nevi and melanomas for some proteins would indicate the usage of a multi-marker expression panel in the differential diagnosis (Table 3). Specially, higher expression of cyclin D1, p21, osteonectin (SPARC) and PKC $\alpha$, and lower expression of 
Ki-67, topoII $\alpha$ and survivin are strongly related to benign behavior.

In summary, we have shown the possibility that a routinely used technique such as immunohistochemistry may aid in differentiating Spitz nevus from melanoma. However, further larger studies including atypical Spitz tumors, lesions that deviate from the typical appearance of Spitz nevi and have an uncertain biological behavior ${ }^{7}$ with long-term follow up, and spitzoid melanomas seem to be mandatory to confirm and build a useful and valuable panel of marker expression in classifying melanocytic lesions.

\section{Acknowledgement}

This paper is supported by grants from the Ministerio de Sanidad y Consumo Fondo de Inversiones Sanitarias (FIS PI 040641) and the Fundacion Mutua Madrileña (FMM 2006-130).

\section{Disclosure/conflict of interest}

The authors declare no conflict of interest.

\section{References}

1 Spitz S. Melanomas of childhood. Am J Pathol 1948;24:591-609.

2 Kapur P, Selim MA, Roy LC, et al. Spitz nevi and atypical Spitz nevi/tumors; a histologic and immunohistochemical analysis. Mod Pathol 2005;18:197-204.

3 Piepkorn M. On the nature of histologic observations: the case of the Spitz nevus. J Am Acad Dermatol 1995;32:248-254.

4 Walsh N, Crotty K, Palmer A, et al. Spitz nevus versus spitzoid malignant melanoma: an evaluation of the current distinguishing histopathological criteria. Hum Pathol 1998;29:1105-1112.

5 Barnhill RL. The Spitzoid lesion: the importance of atypical variants and risk assessment. Am J Dermatopathol 2006;28:75-83.

6 Barnhill RL, Piepkorn M, Busam KJ. The Pathology of Melanocytic Nevi and Malignant Melanoma, 2nd edn. Springer Verlag: New York, 2004.

7 Barnhill RL, Argenyi ZB, From L, et al. Aypical Spitz nevi/tumors: lack of consensus for diagnostic, discrimination from melanoma and prediction of outcome. Hum Pathol 1999;30:513-520.

8 Kaleem Z, Lind AC, Humphrey PA, et al. Concurrent Ki-67 and p53 immunolabeling in cutaneous melanocytic neoplasms: an adjunct for recognition of the vertical growth phase in malignant melanoma? Mod Pathol 2000;13:217-222.

9 Alonso SR, Ortiz P, Pollán M, et al. Progression in cutaneous malignant melanoma is associated with distinct expression profiles. A tissue microarray-based study. Am J Pathol 2004;164:193-203.

10 Benjamini Y, Hochberg Y. Controlling the false discovery rate and practical and powerful approach to multiple testing. J R Stat Soc Series B Stat Methodol 1995;57:289-300.
11 Alonso SR, Tracey L, Ortiz P, et al. A high-throughput study in melanoma identifies epithial-mesenchymal transition as a major determinant of metastasis. Cancer Res 2007;67:3450-3460.

12 Darier J, Civatte A. Naevus ou naevo-carcinoma chez un nourisson. Bull Soc Fr Dermatol Syphiligr 1910;21: 61-63.

13 Smith KJ, Barrett TL, Skelton III HG, et al. Spindle and epithelioid cell nevi with atypia and metastasis (malignant Spitz nevus). Am J Surg Pathol 1989;13: 931-933.

14 Ludgate MW, Fullen DR, Lee J, et al. The atypical spitz tumor of uncertain biologic potential. A series of 67 patients from a single institution. Cancer 2009;115: 631-641.

15 Cerroni L. Spitzoid tumors. A matter of perspectives? Am J Dermatopathol 2004;26:1-3.

16 Bastian BC, Wesselmann U, Pinkel D, et al. Molecular cytogenetic analysis of Spitz nevi shows clear differences to melanoma. J Invest Dermatol 1999;113: 1065-1069.

17 Bastian BC, LeBoit PE, Pinkel D. Mutations and copy number increase of HRAS in Spitz nevi with distinctive histopathological features. Am J Pathol 2000;157: 967-972.

18 Bauer J, Bastian BC. DNA copy number changes in the diagnosis of melanocytic tumors. Pathologe 2007;28: 464-473.

19 Harvell JD, Bastian BC, LeBoit PE. Persistent (Recurrent) Spitz Nevi. A histopathologic, immunohistochemical and molecular pathologic study of 22 cases. Am J Surg Pathol 2002;26:654-661.

20 Harvell JD, Kohler S, Zhu S, et al. High-resolution array-based comparative genomic hybridization for distinguishing paraffin-embedded spitz nevi and melanomas. Diagn Mol Pathol 2004;13:22-25.

21 Gerami P, Jewell SS, Morrison LE, et al. Fluorescence in situ hybridization (FISH) as an ancillary diagnostic tool in the diagnosis of melanoma. Am J Surg Pathol 2009;33:1146-1156.

22 Urso C. A new perspective for Spitz tumors? Am J Dermatopathol 2005;27:364-366.

23 Cerroni L. A new perspective for Spitz tumors? Am J Dermatopathol 2005;27:366-367.

24 Howat AJ, Giri DD, Cotton DW, et al. Nucleolar organizer regions in Spitz nevi and malignant melanomas. Cancer 1989;63:474-478.

$25 \mathrm{Tu}$ P, Miyauchi S, Miki Y. Proliferative activities in Spitz nevus compared with melanocytic nevus and malignant melanoma using expression of PCNA/cyclin and mitotic rate. Am J Dermatopathol 1993;15: 311-314.

26 Bergman R, Kerner H, Manov L, et al. C-fos protein expression in Spitz nevi, common melanocytic nevi, and malignant melanomas. Am J Dermatopathol 1998;20:262-265.

27 Bergman R, Lurie M, Kerner H, et al. Mode of c-myc protein expression in Spitz nevi, common melanocytic nevi and malignant melanomas. J Cutan Pathol 1997; $24: 219-222$.

28 Guttman-Yassky E, Bergman R, Manov L, et al. Human telomerase RNA component expression in Spitz nevi, common melanocytic nevi, and malignant melanomas. J Cutan Pathol 2002;29:341-346.

29 Nagasaka T, Lai R, Medeiros LJ, et al. Cyclin D1 overexpression in Spitz nevi: an immunohistochemical study. Am J Dermatopathol 1999;21:115-120. 
30 Bergman R, Shemer A, Levy R, et al. Immunohistochemical study of p53 protein expression in Spitz nevi as compared with other melanocytic lesions. Am J Dermatopathol 1995;17:547-550.

31 Sparrow LE, Eldon MJ, English DR, et al. P16 and p21WAF1 protein expression in melanocytic tumors by immunohistochemistry. Am J Dermatopathol 1998;20:255-261.

32 Clarke LE, Fountaine TJ, Hennessy J, et al. Cdc7 expression in melanomas, Spitz tumors and melanocytic nevi. J Cutan Pathol 2009;36:433-438.

33 Hafeez Diwan A, Dang SM, Prieto VG, et al. Lack of maturation with anti-leptin receptor antibody in melanoma but not in nevi. Mod Pathol 2009;22: 103-106.

34 Maldonado JL, Timmerman L, Fridlyand J, et al. Mechanisms of cell cycle arrest in Spitz nevi with constitutive activation of the MAP-kinase pathway. Am J Pathol 2004;164:1783-1787.

35 Michieli P, Chedid M, Lin D, et al. Induction of WAF1/ CIP1 by p53-independent pathway. Cancer Res 1994;54:3391-3395.

36 Vidal MJ, Loganzo Jr F, de Oliveira AR, et al. Mutations and defective expression of the WAF1 p21 tumor suppressor gene in malignant melanomas. Melanoma Res 1995;5:243-250.

37 Sauter ER, Yeo UC, Von Stemm A, et al. Cyclin D1 is a candidate oncogene in cutaneous melanoma. Cancer Res 2002;62:3200-3206.
38 Li F, Ambrosini G, Chu EY, et al. Control of apoptosis and mitotic spindle checkpoint by survivin. Nature 1998;396:580-584.

39 Turley H, Comley M, Houlbrook S, et al. The distribution and expression of the two isoforms of DNA topoisomerase II in normal and neoplastic human tissues. Br J Cancer 1997;75:1340.

$40 \mathrm{Mu}$ XC, Tran TA, Ross JS, et al. Topoisomerase II alpha expression in melanocytic nevi and malignant melanoma. J Cutan Pathol 2000;27:242-248.

41 Paradela S, Fonseca E, Pita S, et al. Spitzoid melanoma in children: a clinicopathological study and application of immunohistochemistry as an adjunct diagnostic tool. J Cutan Pathol 2009;36:740-752.

42 Kanter-Lewensohn L, Hedblad MA, Wejde J, et al. Immunohistochemical markers for distinguishing Spitz nevi from malignant melanomas. Mod Pathol 1997;10:917-920.

43 Nasr MR, El-Zammar O. Comparison of pHH3, Ki-67 and survivin immunoreactivity in benign and malignant melanocytic lesions. Am J Dermatopathol 2008; 30:117-122.

44 Koleske AJ, Baltimore D, Lisanti MP. Reduction of caveolin and caveolae in oncogenically transformed cells. Proc Natl Acad Sci USA 1995;92:1381-1385.

45 Dennis JU, Dean NM, Bennett CF, et al. Human melanoma metastasis is inhibited following ex vivo treatment with an antisense oligonucleotide to protein kinase C- $\alpha$. Cancer Lett 1998;128:65-70. 